\title{
La relación entre derecho, técnica y guerra en el pensamiento de Carl Schmitt
}

\author{
The relation between Law, \\ Technique and War in Carl Schmitt's thought
}

GERARDO TRIPOLONE*

\begin{abstract}
Resumen: En el presente trabajo identificamos una posible contradicción en la obra de Carl Schmitt y proponemos una interpretación que la subsanaría. Por un lado, Schmitt fue crítico de la pérdida de una «Idea política» en favor del progreso técnico. Por el otro, añoraba el Ius Publicum Europaeum y la ordenación mundial que éste había logrado. Sin embargo, el Ius Publicum Europaeum fue un producto de la modernidad, era del auge de la técnica y de pérdida de la Idea política católico-medieval. Según nuestra interpretación, esta aparente contradicción tiene solución: el Ius Publicum Europaeum, a pesar de ser un producto de la modernidad, constituye el último intento del Derecho por ser el Kat-echon de la Historia.

Palabras claves: Carl Schmitt, derecho, técnica, guerra.
\end{abstract}

\begin{abstract}
In this paper we identify a possible contradiction in Carl Schmitt's works and propose an interpretation that would remedied. On one hand, Schmitt was critical of the loss of «Political Idea» in favor of technique progress. On other hand, Schmitt longed the global order of Ius Publicum Europaeum. However, Ius Publicum Europaeum is a product of modernity, age of technique boom and loss of MedievalCatholic Idea. According to our interpretation, this apparent contradiction can be solved: the Ius Publicum Europaeum, despite be a product of modernity, was the last attempt of the Law to be a Kat-echon of History.
\end{abstract}

Key words: Carl Schmitt, law, technique, war.

«La religión de los milagros y del más allá se convirtió, sin solución de continuidad, en una religión del milagro técnico, de las conquistas

humanas y del dominio sobre la naturaleza».

Carl Schmitt.

Fecha de recepción: 25/07/2013. Fecha de aceptación definitiva: 10/09/2014.

Becario Doctoral del Consejo Nacional de Investigaciones Científicas y Técnicas de Argentina (Conicet). Doctorando en Derecho y Ciencias Sociales por la Universidad Nacional de Córdoba, Argentina. Tesis: "Carl Schmitt y el factor espacial del derecho internacional”. Docente del Departamento de Ciencias Jurídicas, Universidad Nacional de San Juan, Argentina.

Email: gerardo.tripolone@gmail.com 


\section{Introducción}

El principal problema de la técnica es, para Carl Schmitt, la desespacialización política que produce; el desasentamiento global, la desterritorialización de la vida social. ${ }^{1}$ Cuando Inglaterra se decidió por la existencia marítima no sólo se convirtió en la gran dominadora del mar, también produjo un total «des-asentamiento» de la técnica. ${ }^{2}$ Como dijo Hegel, el elemento principal del progreso técnico es el navío que surca los mares sin lugar fijo, sin posibilidad de asentarse. Marx agregó que el capitalismo, con su progreso técnico incesante, penetra en todas las naciones derribando todas las fronteras.

Un enemigo central de Schmitt fue esa técnica deslocalizada. Producto de una modernidad que se entregó a su supuesta potencia neutralizadora, tomó al mar como elemento y abandonó la tierra firme. En el mar, dice Schmitt, no pueden fijarse límites ni crear un orden jurídico: «El mar no conoce [la] unidad evidente de espacio y derecho, de ordenación y asentamiento». ${ }^{3}$

Pero la técnica es también un agente dañino de la Idea política. En Catolicismo y Forma política Schmitt aborda el concepto de Repräsentation: representación no en sentido jurídico-privado, ni tampoco en sentido de «representantes del pueblo» elegidos por el voto. ${ }^{4}$ Repräsentation en el sentido en que el Papa es vicario de Cristo y representante de la Iglesia. Tiene la dignidad suficiente para sostener en el seno de la Iglesia la complexio oppositorum, es decir, todas las contradicciones que una institución es capaz de contener. Sin embargo, esas contradicciones no impiden reconocer la autoridad del Papa. Esa era la Idea política que, para Schmitt, hacía sostenible en el tiempo el poder de la Iglesia: «Con todo cambio de la situación política cambian aparentemente todos los principios, excepto uno: el poder del Catolicismo»..$^{5}$

Las reflexiones que vinculan técnica y desespacialización política constituyen momentos sumamente atrapantes de la obra del jurista alemán. Sin embargo, hay una zona oscura en el pensamiento schmittiano sobre este tema que quisiéramos analizar en estas páginas. En el momento en que se pone en tensión progreso técnico, cambio en el concepto de guerra y derecho, surge una (aparente) contradicción que es necesario resolver.

Schmitt, como se sabe, reivindicaba la configuración político-jurídica del Ius Publicum Europaeum. Al contrario del derecho internacional surgido con posterioridad a la Primera Guerra Mundial, el antiguo derecho de gentes centrado en Europa era, para el jurista, una

1 Ocaña, E., «Carl Schmitt: Topología de la técnica», Daímon (Murcia), n 13, Julio-Diciembre 1996, p. 35.

2 Pardo, C., «Estudio preliminar», en: C. Schmitt, El valor del Estado y el significado del individuo, edición, estudio introductorio y traducción Celestino Pardo, Centro de Estudios Políticos y Constitucionales, Madrid, 2011, p. CLXVIII.

3 Schmitt, C., Der Nomos der Erde im Völkerrecht des Jus Publicum Europaeum, Duncker \& Humblot, Berlin, 1974, p. 13. [Se cita por la versión en alemán, no obstante, las traducciones han sido corroboradas con la realizada por Dora Schilling Thon publicada en Centro de Estudios Constitucionales, Madrid, 1979].

4 Para los diversos sentidos del concepto de «representación en Schmitt» véase Weber, S., «El principio de representación en Catolicismo romano y Forma política de Carl Schmitt, Deus Mortalis (Buenos Aires), n 4, 2005, pp. 381-399.

5 Schmitt, C., Catolicismo y Forma política [1923], trad. Carlos Ruiz Miguel, Areté grupo editor, Buenos Aires, 2009 , p. 49. 
ordenación clara y previsible, ya que mantenía una precisa identificación de espacios, a la par que limitaba la guerra impidiendo la aniquilación del enemigo.

Ahora bien, esa ordenación fue un producto de la modernidad y, más específicamente, de la creación de los Estados modernos y de la caída del Imperio Medieval Católico. El Ius Publicum Europaeum, tan venerado por Schmitt, es el resultado de una era de tecnificación incesante, secularización y pérdida de la Idea católica. ¿Cómo puede conciliarse el rechazo de Schmitt al progreso técnico que le quita lugar a la Idea política y la añoranza del jurista alemán por la ordenación del Ius Publicum Europaeum? Es que, según Enrique Ocaña, es justamente en el «solar del Estado moderno» donde Schmitt localiza histórica y conceptualmente el problema de la técnica, ${ }^{6}$ justamente en el mismo momento en que se gestaba la nueva ordenación jurídico-internacional tan admirada por el pensador de Plettenberg.

¿Cómo es posible añorar la Idea política católica a la par que se aprecia con tanto énfasis un producto central de la modernidad secularizada? ¿Cómo conciliar el «canto anti-moderno» que constituye, según Celestino Pardo, el pensamiento schmittiano ${ }^{7}$ con su añoranza de la ordenación del antiguo Ius Publicum Europaeum y del poder del Estado moderno?

Esta es una pregunta que, hasta lo que hemos podido indagar, no ha sido planteada ni menos respondida en la literatura sobre Carl Schmitt. Sin embargo, nos parece central para entender el pensamiento del jurista alemán. En estas páginas quisiéramos aportar una posible solución a la aparente aporía. Según nuestro parecer, este problema filosófico-político puede resolverse abordando lo que para Schmitt es el «núcleo de las cosas»: la guerra. ${ }^{8}$

El jurista, sobre todo luego de la Segunda Guerra Mundial, describió en profundidad cómo estaba configurado el antiguo derecho de gentes surgido con posterioridad a la caída del Imperio Medieval Católico. Tres rasgos centrales tenía aquél orden jurídico: clara ordenación del espacio; equilibrio entre los Estados europeos; y, por último, guerras limitadas entre potencias europeas e ilimitadas cuando un Estado europeo conquistaba «territorio libre» (todo lo no-europeo). ${ }^{9}$

Este último rasgo es el más importante en este punto: la guerra estaba limitada entre potencias europeas. Según Schmitt, nadie buscaba la aniquilación del enemigo en la batalla. La guerra estaba permitida pero no para destruir totalmente al enemigo. Lo que se buscaba era hacer cumplir por la fuerza el interés de un Estado, pero no hacer desaparecer al contendiente.

Esta limitación de la capacidad destructiva de la guerra es, según Schmitt, el gran logro del Ius Publicum Europaeum. Esto sólo fue posible porque existía todavía en los siglos XVII y hasta fines del XIX una Idea política que, aunque no cristiana, era clara y precisa. Esta Idea política consistía en sostener una ordenación espacial del mundo que distinguiera los territorios y que limitara la guerra entre potencias europeas. Mantener esa ordenación era la Idea política del Ius Publicum Europaeum y lo logró durante dos siglos y medio.

Según la interpretación del pensamiento schmittiano que propondremos aquí, para el jurista alemán, el cumplimiento de esa Idea política fue el último intento del Derecho por

6 Ocaña, E., op. cit., p. 27.

7 Pardo, C., op. cit., p. CLX.

8 Schmitt, C., Conceptos y posiciones en la guerra con Weimar-Ginebra-Versalles, en: H. O. Aguilar (prólogo y selección de textos), Carl Schmitt, teólogo de la política, Fondo de Cultura Económica, México, 2004, p. 143.

9 Hemos analizado el pensamiento jurídico internacional de Schmitt en Tripolone, G., "La doctrina de Carl Schmitt sobre el Derecho Internacional", Anuario Mexicano de Derecho Internacional, UNAM, Vol. XIV, 2014. 
detener el avance técnico desenfrenado. Allí radica la verdadera importancia de aquélla ordenación jurídica en el conjunto del pensamiento de Carl Schmitt. El Ius Publicum Europaeum no era, para nuestro autor, una etapa más en la historia del derecho internacional. Su caída no implicó, como explican los historiadores de esta rama jurídica, una democratización y un avance hacia un mundo más justo e igualitario. Con la caída del Ius Publicum Europaeum, para Schmitt, el progreso tecnológico se volvió el único objetivo de la política. Sólo entendiendo al Ius Publicum Europaeum como una ordenación destinada a evitar el avasallamiento de la Idea política por la técnica, sólo entendiéndolo como el Kat-echon de la historia en la modernidad, se resuelve la aporía de Carl Schmitt que explicitamos más arriba.

\section{De la limitación de la guerra en el Ius Publicum Europaeum a la aniquilación del enemigo}

El fin de la Guerra de los Treinta Años (guerra que en sus inicios fue de religión) marca el comienzo de una etapa que en el derecho internacional se conoce como el Ius Publicum Europaeum. La disolución del antiguo Imperio Cristiano de la Edad Media (proceso que había comenzado mucho antes de la Paz de Westfalia), afianzó una comunidad europea de Estados soberanos delimitados territorialmente. Entre las características más importantes de este nuevo derecho de gentes, se destacan la soberanía absoluta reconocida por la comunidad internacional y el equilibrio de poder entre naciones.

Para Carl Schmitt, el derecho de gentes del Ius Publicum Europaeum buscaba mantener una ordenación internacional sustentable en el tiempo. El statu quo que debía sostenerse era el del equilibrio entre las potencias europeas, lo cual no impedía los cambios territoriales que no alterasen sustancialmente dicho equilibrio. En teoría, ningún Estado podía erigirse en dominador sobre los demás y todos juntos bregaban por el mantenimiento de ese equilibrio. ${ }^{10}$ Los nuevos Estados soberanos tenían un objetivo claro en las relaciones internacionales: mantener el equilibrio dentro de Europa haciendo que las desigualdades no sean lo suficientemente grandes como para alterar el orden jurídico internacional.

Ese equilibrio contrastaba con el desequilibrio entre Europa y América recientemente descubierta. Siendo un derecho internacional euro-céntrico, las potencias europeas tomaban al Nuevo Mundo como una tierra de nadie a conquistar, partir y dividir entre los Estados. Todo lo no europeo era ajeno a ese «equilibrio» y el territorio fuera de Europa era territorio libre para la conquista. Esta visión europea de superioridad (superioridad espiritual, diría Hegel y lo tomaría también Schmitt), al menos en parte, mantuvo cohesionada a Europa bajo el mismo régimen jurídico internacional. ${ }^{11}$

10 Sin embargo, hay que dejar sentado lo que dice Ramón Campderrich: «Este igual status [entre Estados] se combinó, un tanto contradictoriamente, con la atribución a algunos estados soberanos de un papel tutelar sobre el sistema europeo de estados soberanos». En definitiva, «este principio nunca fue muy efectivo, ya que siempre hubo estados más poderosos y fuertes que otros, grandes potencias que nunca se privaron de intervenir en la situación política de otros estados o, incluso, de destruir a otros estados -como sucedió con los sucesivos repartos de Polonia a fines del siglo XVIII-.» (Campderrich Bravo, R., Derecho, política y orden internacional en la obra de Carl Schmitt (1919-1945), tesis doctoral, Universitat de Barcelona, Barcelona, 2003, p. 11 n. 29 y 30. El autor ha publicado su tesis bajo el título La palabra del Behemoth. Derecho, política y orden internacional en la obra de Carl Schmitt, Trotta, Madrid, 2005).

11 «El sentido y la esencia del derecho internacional cristiano europeo, su ordenamiento fundamental, radican precisamente en el reparto de las nuevas tierras» (Schmitt, C., Tierra y mar. Consideraciones sobre la historia 
Esta cohesión no se perdía por las guerras entre naciones, que estaban permitidas por el Ius Publicum Europaeum y que eran muy frecuentes. Estas guerras enfrentaban a potencias europeas por territorios o intereses europeos y también por el dominio de los territorios libres (todo lo no-europeo). Sin embargo, estas batallas, algunas de las cuales eran muy duras y desgastantes, no hacían perder conciencia de lo común. La guerra era parte de las opciones que los Estados tenían para resolver sus conflictos, pero reconociendo los beligerantes la existencia política del enemigo y la imposibilidad de aniquilarlo. Por más cruentas que hayan sido las batallas, por lo menos hasta las guerras napoleónicas (hiato en la historia del Ius Publicum Europaeum, repuesto recién en el Congreso de Viena de 1815), en ninguna guerra se buscaba la aniquilación del enemigo, sino sólo imponer los intereses propios. ${ }^{12}$

Las guerras terminaban con la «capitulación» del enemigo, nunca con la fórmula impuesta por los Unionistas a los Confederados luego de la Guerra Civil Norteamericana: «unconditional surrender». «Surrender» es un término extraído del derecho mercantil que significa cesión, transferencia. Abraham Lincoln lo utilizó porque los Estados Confederados de América dejaron de existir al fin de la Guerra de Secesión. ${ }^{13}$

Por el contrario, al finalizar las guerras anteriores a la Primera Guerra Mundial (al menos entre potencias europeas), los Estados derrotados firmaban una «capitulación», que no implicaba el cese de la existencia del otro Estado. Sin embargo, luego de la Primera Guerra Mundial, la «unconditional surrender» pasó a ser fórmula canónica que, aunque podría aceptarse en una guerra civil donde la única posibilidad de salida es la destrucción del enemigo, es totalmente ajena a la tradición del derecho internacional moderno. Sin duda, esto estaba mostrando un cambio importantísimo en el orden político-jurídico mundial.

Es este cambio en la forma de entender la guerra y su finalización, el más importante a la hora de comprender lo que nos interesa en este trabajo del pensamiento de Carl Schmitt. Schmitt fue un jurista por demás lúcido en sus análisis y que vivió consciente la caída del antiguo Ius Publicum Europaeum. En reemplazo de este orden jurídico, según el profesor alemán, surgió un nuevo derecho internacional público que sólo en las formas era más democrático y respetuoso de los derechos humanos. Según Schmitt, este nuevo orden jurídico mundial estaba guiado por objetivos económicos e imperialistas ocultos bajo rostros humanitarios. Este nuevo derecho de gentes, como se sabe, no pudo contener la catástrofe de la Segunda Guerra Mundial ni las guerras totales, discriminatorias y de aniquilación que le sucedieron y que todavía hoy vivimos. ${ }^{14}$

universal [1942], trad. Rafael Fernández-Quintanilla, en: H. O. Aguilar (prólogo y selección de textos), Carl Schmitt, teólogo de la política, Fondo de Cultura Económica, México, 2004, p. 375; ver también: Schmitt, C., Der Nomos der Erde..., loc. cit., p. 36).

12 Véase, Bellamy, A., Guerras justas. De Cicerón a Iraq, trad. Silvia Villegas, Fondo de Cultura Económica, Buenos Aires, 2009, p. 128: durante los siglos XVII a XX, las guerras eran legales siempre, y por tanto «los soberanos iniciaban guerras frecuentemente pero limitadas [...] libradas por ejércitos reducidos formados por voluntarios, oficiales y mercenarios, y tenían un impacto reducido en la vida doméstica».

13 Traverso, E., A sangre y fuego. De la guerra civil europea, 1914-1945, trad. Miguel Ángel Petrecca, Prometeo, Buenos Aires, 2009, p. 79.

14 Es esta anticipación a fenómenos actuales lo que explica, en parte, el rebrote de estudios sobre Schmitt, sobre todo en la literatura anglosajona. Véase, Odysseos, L. y Petito, F., «Introducing the international theory of Carl Schmitt: international law, international relations and the present Global Predicament(s)», Leiden Journal of International Law, I.9, 2006, p. 1-7. Sin embargo, otros autores consideran que casi ningún aporte 
Este nuevo orden jurídico mundial permitió que la técnica se convirtiese en el único motor de la humanidad. Fue ese avance técnico lo que posibilitó, en última instancia, la aniquilación sin límite del enemigo. La Modernidad había abandonado el ideal teológico de la Edad Media que Schmitt añoraba. Es en los siglos del Renacimiento que comienzan los avances tecnológicos que sin duda repercuten o se generan en y para la guerra. ${ }^{15} \mathrm{Sin}$ embargo, a la par que la capacidad dañina de las armas aumentaba, el derecho internacional limitaba el uso de la fuerza y, de esta manera, limitaba la técnica: si no se puede destruir totalmente al enemigo, no se necesitan armas de aniquilación.

Con el fin del Ius Publicum Europaeum, según nuestra interpretación del pensamiento schmittiano, el jurista alemán veía la pérdida absoluta de aquélla limitación a la técnica. $\mathrm{Al}$ ser el progreso técnico, en palabras de Ernst Jünger, la Iglesia popular del siglo XX, ${ }^{16}$ éste es libre de crear armas capaces de aniquilar territorios completos. Schmitt veía que ningún orden jurídico internacional era capaz de limitarlo.

Según el jurista alemán, se había perdido la consciencia de lo común en el orden mundial que limitaba la agresión, como sí había durante el Ius Publicum Europaeum. ${ }^{17}$ Ése orden jurídico mundial sí logró detener, hasta un cierto momento y siempre que las guerras eran entre Estados europeos, el avance técnico que luego llevaría a la guerra de aniquilación. ${ }^{18}$ El derecho internacional posterior no logró hacerlo. De allí la crítica a la Sociedad de las Naciones y a toda pretensión de ordenamiento jurídico-mundial que le siguió: no crearon ninguna ordenación capaz de reemplazar a la anterior que limite la guerra.

Los cráteres lunares de Verdún y del Somme, las máquinas de muerte Nazis y las bombas atómicas sobre Hiroshima y Nagasaki, son sólo una muestra de la capacidad técnica de destrucción de los hombres por otros hombres que se abrió cuando la guerra dejó de limitarse. Para el orden mundial actual la limitación de la guerra es imposible. No existe en el derecho internacional actual la posibilidad de limitar el avance arrollador de la técnica en capacidad de destrucción y aniquilación. De hecho, no hay posibilidad de que se acepte tal cosa. La búsqueda persistente de acabar con los criminales «peligrosos para la humanidad» y la emergencia y excepcionalidad permanente en la que vivimos (descripta por Benjamin hace casi un siglo y analizada más recientemente por Giorgio Agamben), impiden cualquier limitación al potencial bélico.

No importa lo que diga la Carta de Naciones Unidas ni los tratados internacionales de derecho humanitario. Hoy en día, al ser toda confrontación «la última guerra de la huma-

puede extraerse del pensamiento internacional de Schmitt. Véase, Elden, S., «Reading Schmitt geopolitically. Nomos, Territory and Großraum», Radical Philosophy, n 161, May/June 2010, pp. 18-26.

15 Maravall, J. A., Estado moderno y mentalidad social. (Siglos XV a XVII), Revista de Occidente, Madrid, 1972, t. II, pp. 521-526.

16 Jünger, E., «La movilización total», en: E. Jünger, Sobre el dolor seguido de La movilización total y Fuego y movimiento, trad. Andrés Sánchez Pascual, Tusquets Editores, Barcelona, 1995, p. 93.

17 Morgenthau parece coincidir en este análisis, ya que, según su visión, es la conciencia de lo común la única razón por la que el derecho internacional puede limitar la guerra (ver Morgenthau, H., «The twilight of international Morality», Ethics and international journal of social, political, and legal philosophy, vol. 58, No. 2, pp. 87-89).

18 «a técnica, porque multiplica la fuerza militar de los Estados, impulsa el salto a la guerra total ya que ante el riesgo, el miedo a la derrota, ninguno de los contendientes deja de servirse de todos los medios con que cuente, que tenga a su disposición» (Pardo, C., op. cit., p. CXCVI). 
nidad» que acabará con los criminales del mundo, éstas se convierten en guerras de aniquilación total donde es necesario utilizar el máximo poder de muerte contra aquellos que subvierten el orden mundial establecido.

\section{Del enemigo al criminal}

Es obvio que durante el Ius Publicum Europaeum en las guerras se buscaba imponer por la fuerza los intereses propios de cada Estado beligerante. ${ }^{19}$ Sin embargo, no se tomaba al enemigo como un criminal que estuviese en falta: «criminal», término que aparecerá en el derecho internacional recién en el siglo XX para intentar juzgar al Káiser Guillermo II y para juzgar con éxito a los jerarcas Nazis, es un concepto propio del derecho penal que se consideraba ajeno al derecho inter-estatal.

Así fue, según Schmitt, desde el siglo XVII hasta el XX. El Ius Publicum Europaeum permitía la guerra pero la limitaba. La posibilidad de la guerra era absoluta y, por ende, se admitía la hostilidad más extrema. Sin embargo, se reconocía un ius in bello que impedía las guerras totales y de aniquilación. La posibilidad de una tal limitación se da únicamente por el reconocimiento mutuo de igualdad entre las potencias europeas:

«La igualdad de los soberanos - escribe Schmitt en El nomos de la tierra- los convierte en partenaires de guerra con derechos idénticos y evita los métodos de guerra de aniquilación». ${ }^{20}$

Así fue, según Schmitt, hasta la Primera Guerra Mundial. Ahora bien, la legitimación del enemigo presupone, como dijimos, que no se lo considere como «inmoral» o «criminal». Es por esto que, en el antiguo derecho de gentes, la justicia de la guerra no estaba en «la concordancia con determinados contenidos de normas teológicas, morales o jurídicas», sino en la «calidad institucional y estructural de las formaciones políticas». ${ }^{21}$ La formalidad y la calidad del enemigo define la guerra: el Iustum bellum es la guerra entre iustis hostis.22

19 La guerra era, como la definía Clausewitz, un «duelo» [Zweikampf] pero en una escala más amplia (Von Clausewitz, K., De la guerra, trad. R. W. de Setaro, Editorial Labor, Buenos Aires, 1984, p. 37). De la misma manera la define Schmitt en Der Nomos der Erde..., loc. cit., p. 113.

20 Schmitt, C., Der Nomos der Erde..., loc. cit. p. 114.

21 Ibídem, pp. 114-115. Hay que recordar que hasta la llamada escolástica española se seguían buscando argumentos de justicia para las guerras. Por ejemplo, Francisco de Vitoria hablaba de guerra legítima cuando los Estados actuaban como delegados del orbe en contra de acciones injustas de otros Estados. Vitoria estaba absolutamente influenciado por el derecho de gentes medieval y, por tanto, su argumentación de la guerra justa se enmarca en la «argumentación teológico-moral y eclesiástica» (Maldonado Simán, B., «La guerra justa de Francisco de Vitoria», Anuario Mexicano de Derecho Internacional (México), vol. VI, 2006, p. 698).

Esto se pierde bastante cuando Grocio, a pesar de traer a colación cuestiones del antiguo concepto de guerra justa, le da una importancia fundamental a la declaración formal de guerra por parte de la autoridad. Con esto, según Truyol y Serra, Grocio se convierte en el iniciador de un «concepto no discriminatorio de la guerra, haciendo de ella una institución de derecho de gentes cuya legitimidad se hará depender de una legalidad vinculada a determinadas formas» (Truyol y Serra, A., Historia de la filosofía del Derecho y del Estado. 2. Del Renacimiento a Kant, Alianza Editorial, Madrid, 1982, p. 162).

22 Schmitt, C., Der Nomos der Erde..., loc. cit., p. 124. 
La limitación de la guerra, en clave schmittiana, se deduce también de la primacía del Estado moderno por sobre cualquier otra entidad. Sólo el Estado tiene el monopolio de la violencia y sólo el Estado tiene el monopolio de la decisión, no sólo sobre el estado de excepción -como dice nuestro autor en Teología política_-23, sino también sobre la determinación de quién es amigo y quién enemigo.

Estamos hablando de la determinación propiamente política de Carl Schmitt, punto neurálgico de la obra del jurista alemán. La decisión entre amigos y enemigos, según Schmitt, el núcleo y presupuesto de la política, lleva ínsita la posibilidad de la guerra. No es que la política sea la guerra o que tenga como objetivo la guerra. Lo que sucede es que la guerra es un «presupuesto» a tener siempre en cuenta.

Puede suceder que en algún momento en las relaciones internacionales -esfera propia de la «alta política»-, se dé el caso extremo y se tenga que llegar a la excepcional situación de guerra. ${ }^{24}$ Allí radica lo central de El concepto de lo político: bajo las decisiones políticas late siempre la posibilidad del enfrentamiento más extremo que es la guerra. Lo que marca el límite de lo político es la decisión sobre quién es el enemigo a enfrentar y quién el amigo.

Esta determinación de lo que es propiamente político implica la aceptación de la guerra por parte de los pueblos. Por más indeseable que sea (como aclara Schmitt que es la gue$\mathrm{rra}^{25}$ ), puede suceder y hay que tenerla en cuenta. Siendo inevitable el conflicto, lo que queda por hacer es limitarlo. Acotarle su capacidad destructiva. Esa era una de las más importantes ventajas del Ius Publicum Europaeum.

\section{El Kat-echon del mundo: Idea política, técnica y derecho}

Sin embargo, hay algo que es importante tener en cuenta. El pensamiento de Carl Schmitt no puede escindirse de su filosofía de la historia que está irremediablemente ligada a la teología. Esta tesis va claramente en contra de la sostenida por autores como Jean-François Kervègan, para quien Schmitt intenta desterrar lo teológico del problema del Ius Publicum Euroaeum. ${ }^{26}$ En el artículo citado, el profesor de la Université Paris I hace un estudio sobre el problema de la teología política en Schmitt. La tesis central del artículo es que ser un «teólogo de la jurisprudencia» es tomar partido por la legitimidad, aun cuando se tenga que ir en contra de la legalidad. El verdadero debate en la filosofía del derecho no sería iusnaturalismo vs. iuspositivismo, sino legalidad vs. legitimidad. Si se quiere ser, como Schmitt, un «teólogo de la jurisprudencia», en ese debate se debe tomar partido por la legitimidad. ${ }^{27}$

23 Schmitt, C., Teología política I. Cuatro capítulos sobre la teoría de la soberanía [1922], en: H. O. Aguilar (prólogo y selección de textos), Carl Schmitt, teólogo de la política, Fondo de cultura económica, México, 2004, p. 28.

24 Schmitt, C., El concepto de lo político [versión de 1963], trad. Rafael Agapito, Alianza Editorial, Madrid, 2009, pp. 58. Más adelante Schmitt argumenta lo siguiente: «No hay que entender por lo tanto que la existencia política no sea sino guerra sangrienta, y que toda acción política sea una acción militar de lucha, como si cada pueblo se viese constante e ininterrumpidamente enfrentado, respecto de los demás, con la alternativa de ser amigo o enemigo; y mucho menos aún que lo políticamente correcto no pueda consistir precisamente en la evitación de la guerra» (ibídem, p. 63).

25 «[L]a guerra y la revolución no son nada "social” ni "ideal"» (ídem).

26 Kervègan, Jean-François, «¿Qué significa ser un teólogo de la jurisprudencia?», Deus Mortalis (Buenos Aires), n 8, 2009, pp. 99-100.

27 Ibídem, pp. 105-106. 
Más allá de esta tesis -discutible de por sí- lo que verdaderamente nos importa de Kervègan es rebatir su postura según la cual el pensamiento sobre el derecho internacional de Carl Schmitt estaría desligado de la teología. Para el profesor francés, esta es la tesis que más problemático hace el concepto de teología política en Schmitt: ¿cómo se puede ser un «teólogo de la jurisprudencia» a la par que se rechaza la teología en el orden internacional? ${ }^{28}$

Kervègan hace, según nuestra interpretación, una lectura errónea de la historia y de la obra de Schmitt. Argumenta, citando Der Nomos der Erde que lo que Schmitt buscaría en el Ius Publicum Europaeum es el carácter neutralizador del Estado moderno, que terminó con las guerras de religión y acabó con la guerra justa, concepto que también sería teológico. ${ }^{29}$ Es decir, Schmitt estaría reivindicado el primado de la política moderna, en principio secularizada y que acabó con las guerras de religión, por sobre una política teologizada que irremediablemente se vuelve hostil hacia la otra religión.

Si ese fuese este realmente el pensamiento de Schmitt, su postura no sería más novedosa que la interpretación de cualquier manual de Teoría del Estado respecto al surgimiento del Estado moderno. Como veremos más adelante, el Ius Publicum Europaeum cumple una función mucho más importante que el de ser el sistema que acogía a los Estados modernos, agentes neutralizadores de las guerras de religión.

Otra postura que separa la teología del pensamiento internacional de Schmitt es la de William Hooker. En efecto, en su libro Schmitt's International Thought también rechaza la posición «histórico-escatológica» que adopta el jurista alemán. En la introducción, Hooker afirma que esa posición resulta un «enigma estéril» («sterile conundrum») en el que Schmitt se coloca entre una «ultra-reaccionaria defensa de la defectuosa forma de Estado y una apocalíptica anticipación de la unidad mundial». ${ }^{30}$ Es por esto que, por más que Hooker extraiga elementos valiosos del pensamiento de Schmitt, desecha la vinculación con su pensamiento teológico.

Para nosotros, separar ambas esferas imposibilita la comprensión de la tesis schmittiana sobre el orden mundial. No pueden separarse y, si el pensamiento teológico hace que toda su teoría sea rechazable, pues entonces deberá asumirse ese extremo, porque escindirlos es imposible. Para nosotros sí existe una relación entre lo teológico en Schmitt y el derecho internacional. Esa relación no podía no estar presente, ya que la teología es quizás una de las pocas cosas que el jurista alemán no abandona nunca en toda su producción intelectual. No hay porción de la obra schmittiana que no esté atravesada por lo teológico y por su catolicismo.

Es desde esta clave que puede entenderse algo central en sus reflexiones sobre el tema planteado en este trabajo: el concepto de Kat-echon. Este concepto es eminentemente teológico: Kat-echon es la fuerza histórica que detiene la venida del anticristo. La Respublica Christiana, es decir, el Imperio medieval cristiano que dominaba Europa Occidental

28 El autor con el que polemizamos comienza su artículo contraponiendo dos frases en apariencia contradictorias de Schmitt. La primera afirma que «yo [Schmitt] soy un jurista y no teólogo». En la segunda, Schmitt establece que «yo soy un teólogo de la jurisprudencia» (ibídem, p. 91).

29 Ibídem, pp. 99-100.

30 Hooker, W., Carl Schmitt's International Thought. Order and Orientation, Cambridge University Press, Cambridge, 2009 , p. 4. 
bajo el mando de los reyes germánicos era, según Schmitt, el Kat-echon de la historia: era quien evitaba que el mundo se perdiera por la venida del anticristo. ${ }^{31}$

Ese Imperio cayó y dejó el paso a los Estados modernos que son el resultado de la secularización de la política y de la vida social. Si los Estados ya no son confesionales, entonces difícilmente puedan ser portadores del Kat-echon, de la fuerza histórica capaz de retardar el anticristo. Desde un punto de vista teológico-político, este es el problema interpretativo que quisiéramos responder aquí. El Estado sería, a partir de la modernidad, un producto técnico sin sustento teológico. El mismo Schmitt lo pone de manifiesto en El Leviathan en la Teoría del Estado de Thomas Hobbes. El Estado es

«el primer producto de la época técnica, el primer mecanismo político de gran estilo [...]. En este tipo de Estado no sólo se da ya el supuesto sociológico e histórico de la época técnica industrial siguiente, sino que él mismo es obra típica y aun prototípica de la nueva época técnica». ${ }^{32}$

En parte es por este hecho que a Schmitt le interesó la obra de Thomas Hobbes. En su libro sobre el Leviathan, nuestro autor aclara que, para el filósofo inglés, la imagen del Leviatán representa: una bestia bíblica, un gran hombre, un dios mortal y una máquina.33 Esta última caracterización es la que más nos importa: el Leviatán, el Estado, sería una gran máquina que, como vimos en la cita más arriba, constituye «el primer mecanismo político de gran estilo». El Estado es la máquina más impresionante de la modernidad. No hay aparato técnico que lo iguale.

Es por eso que la pregunta teológico-política por la relación entre el Kat-echon y la visión schmittiana del derecho internacional moderno debe ser analizada a través del cuestionamiento que ha guiado este trabajo: ¿cómo se entiende que Schmitt haya apoyado de manera tan enfática el Ius Publicum Europaeum, ordenación basada en la «obra típica y aun prototípica de la nueva época técnica», como es el Estado? A su vez, el avance tecnológico que tiene lugar en el amanecer de la Edad Moderna, ¿no debería contrastar con el rechazo schmittiano a la técnica?

Como dijimos en el primer acápite, a partir del siglo XV, los ejércitos comienzan tecnificarse y, por ende, a tener una capacidad destructiva desconocida en la Edad Media (capacidad que, como quedó claro más arriba, estaba limitada por el derecho internacional). José Antonio Maravall comenta la transformación de la guerra, a partir del siglo XV y XVI, en un «arte» en el sentido de técnica, de ciencia rigurosa. La victoria en la batalla dejó de ser patrimonio del valor y el esfuerzo humano para ser la conclusión de los estudios técnicos y científicos. Según Maravall, en esa época comenzó a verse una tendencia a «eliminar el factor físico y el factor moral del elemento humano, para destacar predominantemente el factor intelectual» ${ }^{34} \mathrm{La}$ formación militar no apuntó más a la «ética

31 Schmitt, C., Der Nomos der Erde..., loc. cit., pp. 28-29.

32 Schmitt, C., El Leviathan en la Teoría del Estado de Thomas Hobbes, trad. Francisco Javier Conde, Comares, Granada, 2004, p. 29.

33 Ibídem, p. 14.

34 Maravall, J. A., op. cit., p. 521. 
de caballeros», como sucedía en la Edad Media, enfocándose en «una técnica militar. El nuevo "arte de la guerra" no es una sabiduría, sino una ciencia». ${ }^{35}$

¿Cómo compatibilizar este emerger de la técnica con el apoyo del jurista alemán al derecho internacional moderno? Lo que Schmitt rechazaba de la técnica es su ausencia de Idea política, su supuesta neutralidad que en verdad no es tal. ${ }^{36}$ La técnica, para Schmitt, sirve tanto a la ideología liberal-capitalista como a la comunista-soviética. De ahí su apego a la representación de la Iglesia católica que se orienta a un fin concreto basado en una Idea política y no se entrega, según nuestro autor, a los dominios supuestamente neutrales de la técnica. La técnica no conoce fines sino medios, dice Schmitt. ${ }^{37}$

Se ve por qué Schmitt valora de tan buena forma el antiguo Imperio medieval y católico. Ese Imperio sí tenía una Idea política clara y la sustentó hasta la Reforma: constituía el Katechon que demoraba al anticristo. No hay, para Carl Schmitt, Idea política más central que ésta. En cambio, «una sociedad construida sólo sobre el progreso técnico», argumenta en Catolicismo y Forma política, «pronto se habría aniquilado a sí misma y a su técnica». ${ }^{38} \mathrm{Si}$ la base de una sociedad es el avance y el progreso tecnológico, según Schmitt, ésta caerá en la ruina en un corto plazo.

Si aceptamos que en la Edad Moderna se dieron los cambios que comenta José Antonio Maravall y que vimos someramente párrafos más arriba, vale insistir con nuestra pregunta: ¿Cómo compatibilizar el aumento de la técnica en la Edad Moderna y el abandono de la Idea política católica de la Edad Media, con la ferviente defensa de Schmitt al Ius Publicum Europaeum surgido en la modernidad? Es hora de dar una respuesta.

\section{El Ius Publicum Europaeum como Kat-echon de la Historia}

La respuesta que podemos dar es la siguiente: el derecho internacional que rigió entre el siglo XVII y el XX -el denominado Ius Publicum Europaeum- sería, a los ojos de Schmitt, el último intento de detener el avance irrefrenable de la técnica por sobre la política y, por tanto, funcionaría como último Kat-echon de la historia. El Ius Publicum Europaeum constituyó la fuerza histórica de la modernidad que evitaba la abolición de la Idea política por la técnica.

Este intento se basaba en una conciencia de ordenación común que no estaba formalizada en normas positivas, sino que surgía y se mantenía por el convencimiento en la necesidad del equilibrio entre las Naciones y el respeto mutuo que se tenían los diferentes monarcas. Esto hacía que, a pesar de la legalidad de la guerra, nadie se erigiese en potencia dominante sobre las demás ni buscase la aniquilación del otro (al menos esa es la interpretación histórica que hace Schmitt que es, por supuesto, muy discutible).

Éste era el gran limitador de la técnica: nadie buscará armas que destruyan completamente al otro si esto no está permitido y es respetado por todos. Este respeto sólo era posi-

35 Ibídem, p. 523.

36 «La técnica es sólo instrumento y arma, y porque sirve a cualquiera no es neutral» (Schmitt, C., «La era de las neutralizaciones y las despolitizaciones» [1932], en: C. Schmitt, El concepto de lo político [versión de 1963], trad. Rafael Agapito, Alianza Editorial, Madrid, 2009, p. 118).

37 Schmitt, C., Catolicismo..., loc. cit., p. 63.

38 Ibídem, p. 78. 
ble porque existía una conciencia de lo común que se basaba en una Idea política que era compartida por todos los actores de la comunidad internacional. Era esta Idea la que cumplía la función de Kat-echon en el mundo moderno y la que detuvo por dos siglos y medio el triunfo final de la técnica por sobre una Idea política. Allí radica el verdadero valor del Ius Publicum Europaeum, último intento del Derecho por detener la técnica.

Luego de la Gran Guerra, para Schmitt, esta Idea se derrumba. La técnica no puede detenerse y la lucha se vuelve ilimitada. En lugar del enemigo aparece el criminal que debe ser aniquilado. Todos los medios técnicos son válidos si se utilizan para acabar con los enemigos de la humanidad que alteran el orden económico mundial. Por eso las guerras no pueden no ser de aniquilación: el enemigo no es un igual, sino un criminal que hay que exterminar utilizando toda la capacidad tecnológica.

Carl Schmitt vio que todas sus ideas políticas no se condecían con la entrega de la humanidad a los ideales económicos y de dominio técnico por sobre la política, la moral y el derecho. He ahí, según nuestro parecer, su admiración por la ordenación del antiguo Ius Publicum Europaeum a pesar de ser un eminente producto de la modernidad tecnificada. El orden posterior a Versalles, orden que no podía contener la técnica y su capacidad destructiva, es lo opuesto al Ius Publicum Europaeum.

A pesar de ser un producto secularizado, el derecho de gentes moderno era una ordenación clara contra uno de los principales enemigos de Schmitt: el progreso técnico sin Idea política. Sólo si se entiende al Ius Publicum Europaeum como el Kat-echon del mundo moderno, puede compatibilizarse la aparente contradicción en la obra schmittiana que ha guiado estas páginas. Ante la modernidad tecnificada que diluye la Idea política, Carl Schmitt decide por aquello que creía podía servir de Kat-echon: la espacialización de la política en torno a nuevas divisiones del mundo. Esa Idea tenía un modelo en la historia: el Ius Publicum Europaeum.

\section{Referencias}

Bellamy, Alex, Guerras justas. De Cicerón a Iraq, trad. Silvia Villegas, Fondo de Cultura Económica, Buenos Aires, 2009.

Campderrich Bravo, Ramón, Derecho, política y orden internacional en la obra de Carl Schmitt (1919-1945), tesis doctoral, Universitat de Barcelona, Barcelona, 2003.

Elden, S., «Reading Schmitt geopolitically. Nomos, Territory and Großraum», Radical Philosophy, $\mathrm{n}^{\circ} 161$, May/June 2010.

Hooker, William, Carl Schmitt's International Thought. Order and Orientation, Cambridge University Press, Cambridge, 2009.

Jünger, Ernst, «La movilización total», en: E. Jünger, Sobre el dolor seguido de La movilización total y Fuego y movimiento, trad. Andrés Sánchez Pascual, Tusquets Editores, Barcelona, 1995.

Kervègan, Jean-François, «¿Qué significa ser un teólogo de la jurisprudencia?», Deus Mortalis (Buenos Aires), n 8, 2009.

Maldonado Simán, Beatriz, «La guerra justa de Francisco de Vitoria», Anuario Mexicano de Derecho Internacional (México), vol. VI, 2006. 
Maravall, José Antonio, Estado moderno y mentalidad social. (Siglos XV a XVII), Revista de Occidente, Madrid, 1972.

Morgenthau, Hans, «The twilight of international Morality», Ethics and international journal of social, political, and legal philosophy, vol. 58, No. 2, Chicago University Press, pp. 79-89.

Odysseos, Louza y Petito, Fabio, «Introducing the international theory of Carl Schmitt: international law, international relations and the present Global Predicament(s)», Leiden Journal of International Law, I. 9, 2006.

Ocaña, Enrique, «Carl Schmitt: Topología de la técnica», Daímon (Murcia), n 13, JulioDiciembre 1996.

Pardo, Celestino, «Estudio preliminar», en: C. Schmitt, El valor del Estado y el significado del individuo, edición, estudio introductorio y traducción Celestino Pardo, Centro de Estudios Políticos y Constitucionales, Madrid, 2011.

Schmitt, Carl, Teología política I. Cuatro capítulos sobre la teoría de la soberanía [1922], en: H. O. Aguilar (prólogo y selección de textos), Carl Schmitt, teólogo de la política, Fondo de cultura económica, México, 2004.

- Catolicismo y Forma política [1923], trad. Carlos Ruiz Miguel, Areté grupo editor, Buenos Aires, 2009.

- «La era de las neutralizaciones y las despolitizaciones» [1932], en C. Schmitt, El concepto de lo político [versión de 1963], trad. Rafael Agapito, Alianza Editorial, Madrid, 2009.

-, Conceptos y posiciones en la guerra con Weimar-Ginebra-Versalles, en: H. O. Aguilar (prólogo y selección de textos), Carl Schmitt, teólogo de la política, Fondo de Cultura Económica, México, 2004.

-, Tierra y mar. Consideraciones sobre la historia universal [1942], trad. Rafael FernándezQuintanilla, en: H. O. Aguilar (prólogo y selección de textos), Carl Schmitt, teólogo de la política, Fondo de Cultura Económica, México, 2004.

-, El Leviathan en la Teoría del Estado de Thomas Hobbes, trad. Francisco Javier Conde, Comares, Granada, 2004.

-, Der Nomos der Erde im Völkerrecht des Jus Publicum Europaeum [1950], Duncker \& Humblot, Berlin, 1974.

-, El concepto de lo político [versión de 1963], trad. Rafael Agapito, Alianza Editorial, Madrid, 2009.

Traverso, Enzo, A sangre y fuego. De la guerra civil europea, 1914-1945, trad. Miguel Ángel Petrecca, Prometeo, Buenos Aires, 2009.

Tripolone, Gerardo, "La doctrina de Carl Schmitt sobre el Derecho Internacional", Anuario Mexicano de Derecho Internacional, UNAM, Vol. XIV, 2014.

Truyol y Serra, Antonio, Historia de la filosofía del Derecho y del Estado. 2. Del Renacimiento a Kant, Alianza Editorial, Madrid, 1982.

Von Clausewitz, Karl, De la guerra, trad. R. W. de Setaro, Editorial Labor, Buenos Aires, 1984.

Weber, Samuel, «El principio de representación en Catolicismo romano y Forma política de Carl Schmitt, Deus Mortalis (Buenos Aires), n 4, 2005. 
